\title{
EIN ISOLIERTES KÖRPERGRAB AUS DEM 1. JH. N. CHR. VOM GERMANISCHEN FÜRSTENSITZ IN ZOHOR, WESTSLOWAKEI ${ }^{1}$
}

\author{
K R I S T I A N E L S C H E K 뭉
}

\begin{abstract}
An Isolated Skeletal Grave from the $1^{\text {st }}$ Century AD from the Germanic Nobility Seat in Zohor, Western Slovakia. Skeletal graves from the Region north of the Middle Danube are quite rare, because the cremation burials significantly predominated. In Zohor, beside richly equipped princely skeletal graves, also one isolated female skeletal grave of a 50-60 years old woman was excavated. It was found in the settlement area from the $1^{\text {st }} \mathrm{c}$. AD, the equipment of the grave was rather poor than rich: two brooches Almgren 68, a small iron knife, a bronze needle und two small ceramic vessels. The median of the absolute ${ }^{14} \mathrm{C}$ dating was about $40 \mathrm{AD}$.
\end{abstract}

Keywords: Slovakia, $1^{\text {st }}$ century AD, Germans, skeletal grave, absolute dating.

\section{DIE FUNDSTELLE}

Die polykulturelle Fundstelle von Zohor-Flur Piesky mit der Besiedlung vom Neolithikum, der Bronzezeit, Latènezeit, Römischen Kaiserzeit, und dem Frühmittelalter ist seit den 30-er Jahren des 20. Jahrhunderts bekannt. Die Fundstelle befindet sich an der Bernsteinstraße, die entlang des Marchflusses nach Norden führt (Abb. 1; 2). Sie liegt auf einem Sand/Schotterterrasse über dem Überschwemmungsgebiet des Marchflusses etwa $14 \mathrm{~km}$ nördlich vom Zusammenfluss der Donau mit der March entfernt. Beim Sand- und Schotterabbau wurden hier mehrere Fürstengräber aus der Römischen Kaiserzeit in den 30-er bis 50-er Jahren des 20. Jh. gestört, wobei ein Teil der Funde in die Museen von Bratislava und Martin kam (Kolník 1959; Kraskovská 1959; Ondrouch 1957). Weitere Rettungsgrabungen realisierte hier die Archäologische Abteilung des Slowakischen Nationalmuseums (z. B. Studeníková 1978), die Prospektion und weitere Rettungs- und Forschungsgrabungen werden hier seit 1994 vom Archäologischem Institut der SAW realisiert. ${ }^{2}$ Seit 1994 konnten etwa 100 Siedlungsobjekte und 24 Brandgräber vom 1.-3. Jahrhundert, ein neues Fürstengrab Nr. 6-Objekt 217/2010 der sog. Lübsow/Lubieszewo-Gruppe vom 2. Jh. und das hier behandelte KörpergrabObjekt 230/2010 vom 1. Jh. untersucht werden.

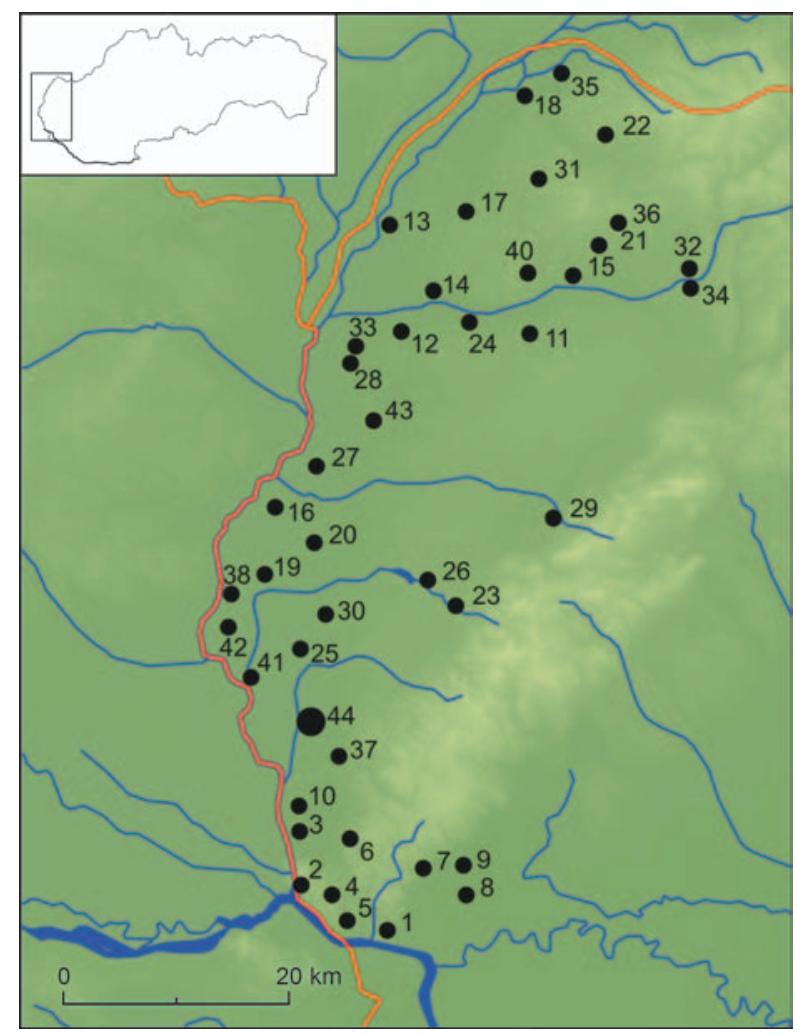

Abb. 1. Marchgebiet mit Fundstellen auf slowakischem Gebiet aus der Römischen Kaiserzeit. Fundstelle Zohor ist unter Nr. 44 situiert.

\footnotetext{
${ }^{1}$ Der Beitrag entstand im Rahmen des Grantprojektes VEGA Nr. 2/0001/18, und ist dem Kollegen PhDr. Karol Pieta, DrSc., zum 80. Geburtstag gewidmet.

${ }^{2}$ K. Elschek.
} 


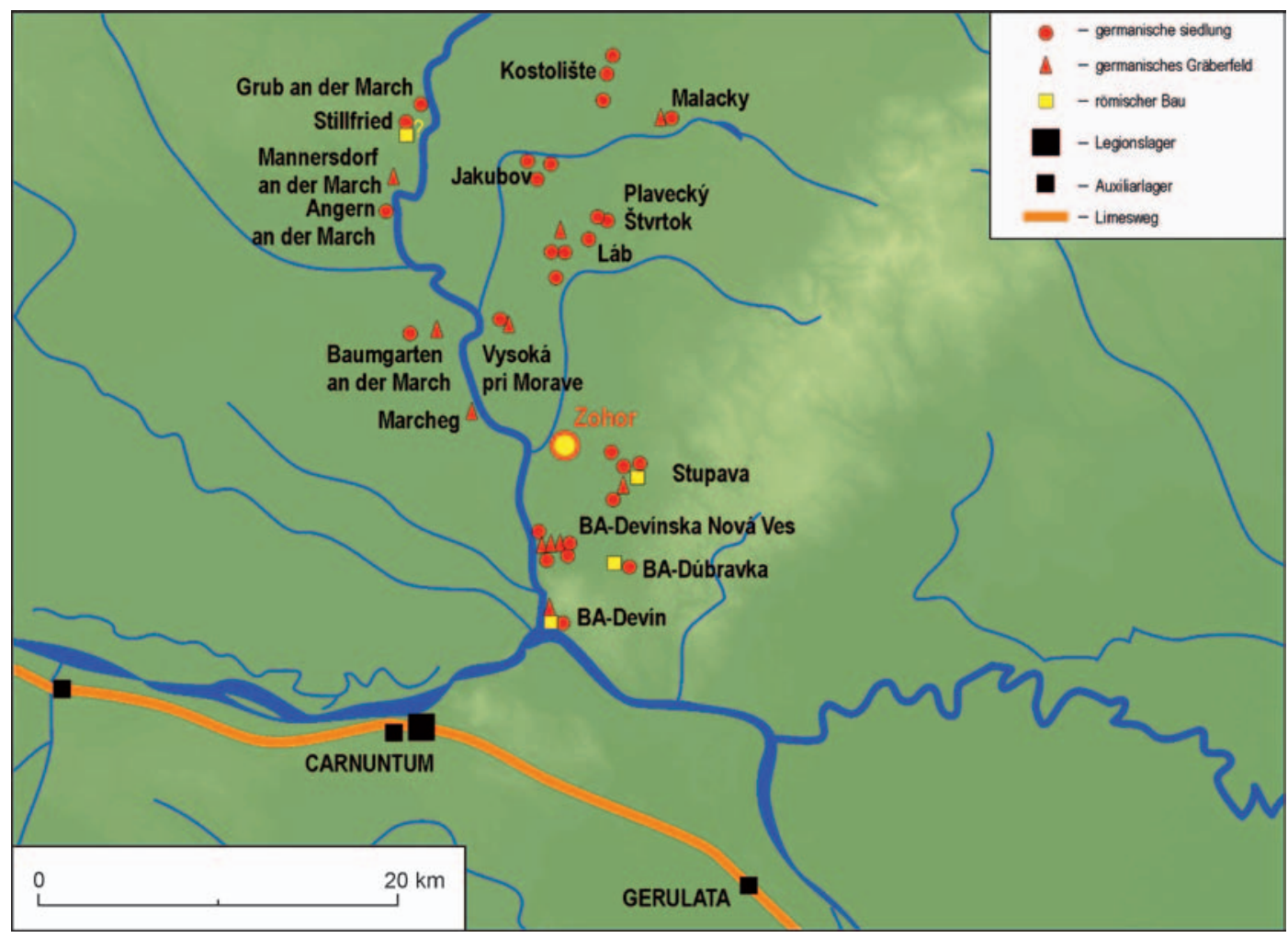

Abb. 2. Südliches Marchgebiet mir Fundstellen aus der Römischen Kaiserzeit.

$\mathrm{Zu}$ weiteren Befunden gehören ein Hortfund von Bronzegefäßbruchstücken (Elschek 2002), ein Sepulkrakobjekt (Elschek/Rajtár/Varsik 2011), weitere Funde vom Brandgräberfeld kamen ins Slowakische Nationalmuseum.

\section{KÖRPERGR ÄBER IN BÖHMEN UND IM NORDDANUBISCHEN BARBARIKUM WÄHREND DES 1. JH.}

Während der Römischen Kaiserzeit wurde in Böhmen und dem norddanubischen Barbarikum bei den Germanen die Brandbestattung auf Nekropolen in Nähe von Siedlungen bevorzugt, so wie das auch in Zohor der Fall ist. Selten kommen germanische Körpergräber einzeln oder in kleinen Gruppen vor. Schon J. Lichardus (1984, 54-56) stellte beim birituellen Gräberfeld von Abrahám, das weiter unten behandelt wird fest, daß die Körpergräber eine geschlossene Gruppe im Süden des Gräberfelds bildeten. Erst später kamen südlich und östlich dieser Gruppe weitere jüngere Brandgräber dazu, wobei die Körpergräbergruppe respektiert blieb. Eine spezielle Problematik stellen die Körpergräber mit fürstlicher Ausstattung der sog. Lübsow-Lubieszewo Gruppe vor (Eggers 1949-1950; Schuster 2010). Diese Gräber liegen fast ausschließlich isoliert von den Brandgräberfeldern, so wie das auch in Zohor der Fall ist (Elschek 2013b).

In Böhmen befaßte sich mit den germanischen Körpergräbern während der Stufe B1 der Römischen Kaiserzeit nach J. Lichardus (1984, 48-51) auch E. Droberjar (2006, 650-652, 695-697). Er führt hier 36 Körpergräber an die nur 6,4 \% der Gräber aus der Zeitstufe B1 nach H. J. Eggers (0-50 n. Chr.) bilden (Eggers 1951). Die Gräber kommen nach E. Droberjar in Böhmen entweder einzeln oder in kleinen Gruppen von 2-4 Körpergräbern vor, wobei sie sich in der Regel außerhalb von zeitgleichen Brandgräberfeldern befinden. Er stellte weiter fest, daß die Körpergräber der Stufe B1 in Böhmen viel zahlreicher als in Mitteldeutschland sind wo er nur 7 Körpergräber aus dieser Zeit anführt (Droberjar 2006, 650).

Im norddanubischen Barbarikum sind Körpergräber aus der Älteren Römischen Kaiserzeit auch nicht zahlreich vertreten. Aus Mušov in Südmähren stammt ein Körpergrab von der Flur „U Sv. Jána“ das aber wahrscheinlich schon in die Stufe B2 gehört, möglicherweise stammt auch die ältere Komponente vom hiesigen Königsgrab aus der Flur Neurissen aus der Stufe B1 (Droberjar 2006, 650). Aus Velatice stammen zwei Körpergräber Nr. 3 und 20 (Jílek) Kuča/Sojková 2011, 242, Abb. 5: 3, 4; Taf. III; VIII). Zu den Beigaben vom Körpergrab Nr. 17 (bzw. jetzt 
Tab. 1. Körpergräber aus Abrahám und Sládkovičovo (Südwestslowakei).

\begin{tabular}{|c|c|c|c|c|c|c|c|c|}
\hline Grab & Fibel & Gefäß & Nadel & Nähnadel & Andere & Datierung & Geschlecht & Alter \\
\hline \multicolumn{9}{|c|}{ Abrahám - Körpergräber } \\
\hline 3 & A68 (3 St.) & 1 & 1 & 1 & - & B1c & Frau & $16-18$ \\
\hline 4 & A67 (2 St.) & 1 & - & - & Armring & B1b & Frau & $40-50$ \\
\hline 11 & - & - & - & - & Feuerstahl & ? & Mann & - \\
\hline 12 & A68 & 1 & - & - & - & B1c & Frau & $30-40$ \\
\hline 13 & - & 1 & - & - & - & $?$ & - & - \\
\hline 121 & A68 (2 St.) & - & - & - & Bronzegefäß (2 St.) & B1c & Mann & $50-60$ \\
\hline 124 & A67 + römische Fibel & 1 & - & - & - & $B 1 b-c$ & Kind & - \\
\hline 135 & A68 (3 St.) & - & - & - & - & B1c & Frau & $40-60$ \\
\hline $135 a$ & - & - & - & - & - & - & Kind & $8-10$ \\
\hline 138 & A45 & - & - & - & Gürtelbeschlag & $\mathrm{B} 1 \mathrm{~b}-\mathrm{C}$ & Frau? & - \\
\hline 140 & A56 & - & - & - & - & B1c & Erwachsen & - \\
\hline 144 & $A 45+49+55$ & 1 & - & - & - & B1b & Frau & $50-60$ \\
\hline $145 \mathrm{~A}$ & - & - & - & - & - & $?$ & - & - \\
\hline \multicolumn{9}{|c|}{ Sládkovičovo - Körpergräber } \\
\hline 27 & $A 69+A 145$ & 2 & - & - & - & B2a & - & - \\
\hline 28 & A60 & 1 & 1 & - & - & B2a & - & - \\
\hline 31 & - & - & - & - & - & $?$ & - & - \\
\hline 39 & A68 & - & - & 1 & - & B1c & - & - \\
\hline 40 & - & - & - & - & - & $?$ & - & - \\
\hline 41 & - & - & - & - & Messer & ? & - & - \\
\hline
\end{tabular}

Nr. 20) ${ }^{3}$ aus Velatice gehörte auch eine Fibel vom Typ Almgren 68 (Tejral 1977, 323-324, Abb. 16: 7). Dieser Fibeltyp ist auch in Körper- und Brandgräbern des birituellen Gräberfelds von Mikulov vertreten, wo 16 Skelettgräber und 19 Brandgräber abgedeckt aber bisher nicht zusammenfassend publiziert wurden (Peškař 1972, 36, Taf. 10: 1; Tejral 1977, 324, Abb. 18: 7-9).

Aus Niederösterreich stammen zwei Körpergräber aus der frühen Kaiserzeit aus Schleinbach (Lauermann 2017, 241; Mitscha-Märheim 1930; Pollak 1980, 119), weitere Brand- und Körperbestattungen sind auch vom Gräberfeld aus Baumgarten an der March bekannt, vom weiblichen Körpergrab des 1. Jh. aus der Fundstelle 6 stammen u. a. norischpannonische Trachtbestandteile und ein römischer Spiegel (Adler 1976, Abb. 10-15; Garbsch 1965, 224;
Pollak 1980, 11-13, Taf. 3; 4). Das Körpergrab mit reicher Bestattung aus Neuruppersdorf wird zu den Fürstengräbern der Lübsow-Gruppe gereiht (Adler 1975), allerdings gehört dieses Grab wahrscheinlich schon in die Zeitphase B2.

In der Westslowakei wurden mehrere Körpergräber im Rahmen der Brandgräberfelder von Abrahám und Sládkovičovo östlich der Kleinen Karpaten untersucht (Kolník 1980). Nur einige Körpergräber gehören wahrscheinlich noch in die Zeitphase B1b (25-50 n. Chr.), ${ }^{4}$ die meisten dann in die Phase B1c (50-70 n. Chr.). ${ }^{5}$ In Abrahám war die Orientierung der Körpergräber vorwiegend NW-SO und $\mathrm{W}-\mathrm{O}$ wobei sich in den Körpergräbern von Abrahám und Sládkovičovo keine Waffen befanden (Lichardus 1984, 52-56), wie das auch bei den Fürstengräbern der Lübsow Gruppe der Fall ist (Tab. 1).

\footnotetext{
${ }^{3}$ Jetzt nach neuer Nummerierung Grab Nr. 20 (vorher als Nr. 17 publiziert) das etwas abseits von den Brandgräbern situiert war (nach Jílek/Kuča/Sojková 2011, 242).

4 Nach Kolník 1977, 149-159.

5 Nach Kolník 1977, 159-161.
} 

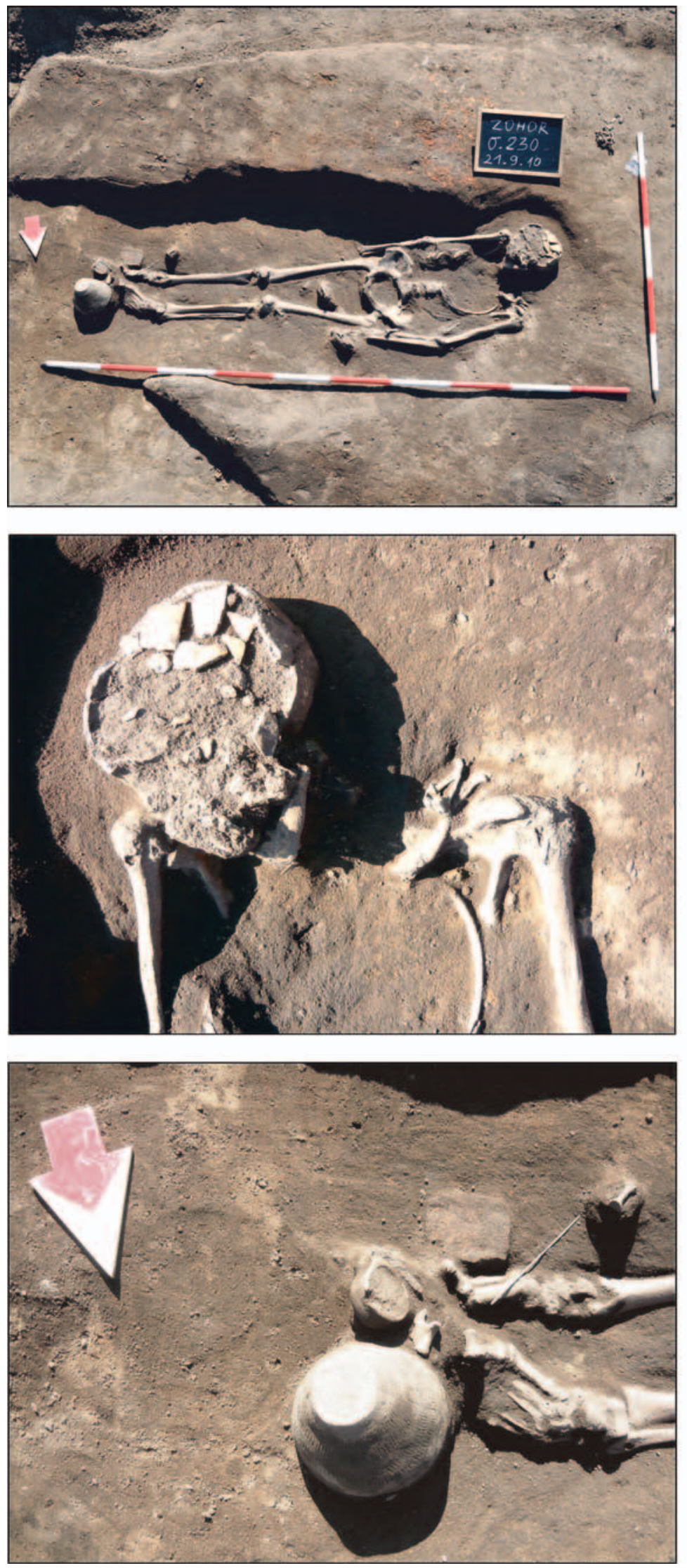

Abb. 3. Zohor-Piesky. Körpergrab-Objekt 230/2010. 


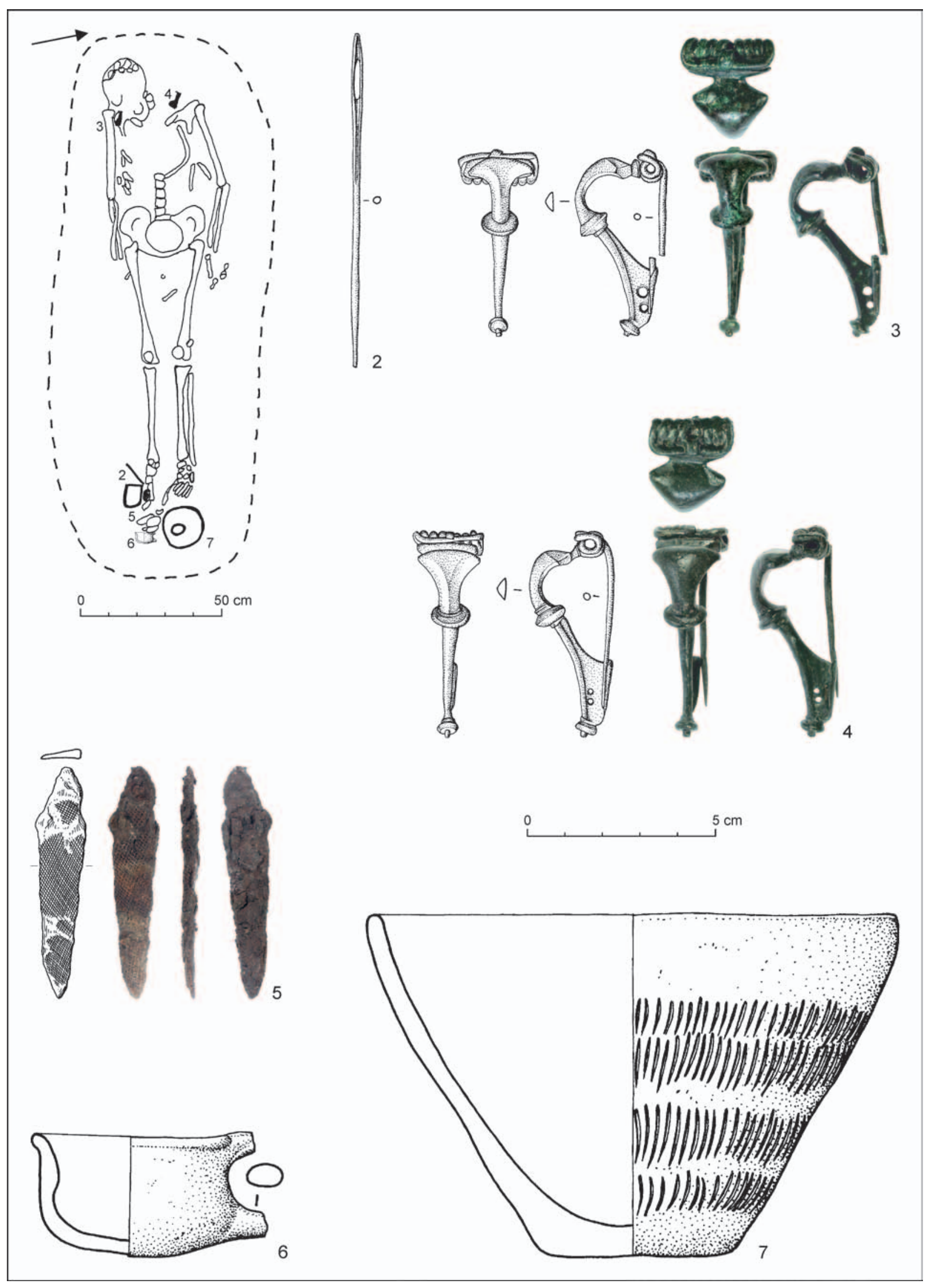

Abb. 4. Zohor-Piesky. Körpergrab-Objekt 230/2010. 2-4 - Bronze; 5 - Eisen; 6, 7 - Keramik. 


\section{KÖRPERGRAB-OBJEKT 230/2010}

Während der Rettungsgrabung im Jahr 2010 wurde in Zohor ein einzelnes seicht vertieftes Körpergrab untersucht. Das Skelettgrab lag an der Kante Humus/Mutterboden. Es war im germanischen Siedlungsbereich vom 1. Jh. n. Chr. situiert. Etwa $30 \mathrm{~m}$ in nördlicher Richtung wurde das germanische Fürstengrab Nr.6-Objekt 217/2010 von der 1. Hälfte des 2. Jh. untersucht, in nordöstlicher Richtung befand sich das ausgedehnte germanische Brandgräberfeld vom 1.-3. Jh. (Elschek 2007; 2013b; 2014a; 2014b), in nördlicher und nordöstlicher Richtung befanden sich weitere Abschnitte der germanischen Zentralsiedlung vom 1.-4. Jh. (Elschek 1997; 2011; 2013a; 2015). Die Tote lag in gestreckter Lage am Rücken. Nach der anthropologischen Analyse handelte es sich bei der Toten um eine für diese Zeit alte Frau von 50-60 Jahren die etwa 161-164 cm groß war und an Arthrose litt. ${ }^{6}$ Die entwickelten Muskelansätze deuten auf eine relativ schwere Arbeit, die die Frau in ihrem Leben verrichtete. Der Grund warum die Tote isoliert im Siedlungsbereich des 1. Jh. und nicht am Brandgräberfeld bestattet wurde ist fraglich, es ist möglich, daß sie eine spezielle Rolle im Rahmen der hiesigen Kommunität erfüllte oder handelte es sich um eine körperbehinderte Frau.

An den Schultern der Bestatteten befanden sich je eine Fibel Almgren 68 und bei den Füßen zwei kleine keramische Gefäße, ein Eisenmesser und eine bronzene Nähnadel (Abb. 3; 4: 1). Die Fibeln Almgren 68 werden vorwiegend um die Mitte des 1. Jh. und während des 3. Viertels des 1. Jh. getragen. Die späten Exemplare des Typs Almgren 68 mit deutlich S-förmig gebogenem Körper waren wahrscheinlich auch noch in flavischer Zeit in Verwendung. Nach der Analyse von I. Peškař werden Fibeln vom Typ Almgren 68 seit den 30-er bis 70-er Jahren getragen (Peškar̆ 1972, 77, 78). Der Verbreitung des Überganstyps Almgren 67/68 und dem Typ Almgren 68 im Barbarikum widmete sich M. Mączyńska, sie datiert den Typ Almgren 68 in die claudische bis vespasianische Zeit (Mączyńska 2001). Am Magdalensberg in der Provinz Noricum gehören Fibeln vom Typ Almgren 68 und Halbfabrikate von diesen etwa in die claudische Zeit - ca. 35/40-50 n. Chr. (Sedlmayer 2009, 155-162, Abb. 107; Taf. 20-22). Die Produktion von Fibeln des Typs Almgren 68 ist auch in der Nachfolgersiedlung vom Magdalensberg in Virunum belegt (Cociș 2019, 62, 63).

Zum Körpergrab-Objekt 230/2010 zeitlich verwandte Körpergräber mit 1-3 Fibeln des Typs Almgren 68 wurden in der Südwestslowakei in birituellen Gräberfeldern Abrahám (Gräber 3, 12, 121, 135) und Sládkovičovo (Grab 39) untersucht (Tab. 1).
Weitere Funde vom Grab tragen zur Datierung nicht entscheiden bei, die Nähnadel und das Messer mit Geweberest waren während der ganzen römischen Kaiserzeit in Verwendung. Nach vorläufiger Analyse von T. Štolcová handelt es sich beim Geweberest in dem das kleine Messer eingepackt wurde um ein leinwandiges Gewebe. Der Textilabdruck ist auf einer Seite und der Messerkante erhalten geblieben. Die zwei kleinen Keramikgefäße sind auch keine typischen Repräsentanten von germanischen Keramikformen des 1. Jh. Das Miniaturgefäß - kleine Henkeltasse hat fürs 1. Jh. Parallelen in der Südwestslowakei, in Sládkovičovo-Grab 77 (Kolník 1980, 323, Grab 77 g) und Bratislava-Dúbravka-Objekt 1/83 (Elschek 2017, 175, Taf. I: 9). E. Droberjar reihte kleine Henkeltassen vom 2. Jh. aus Südmähren zum Typ 5300 (Droberjar 1997, 62). Miniaturgefäße vom quadischen Gebiet bearbeitete E. Krekovič (2014). Der Problematik der Miniaturgefäße in der Slowakei wurde ein Kolloquium gewidmet (Turčan 2016), ähnliche kleine Keramiktassen waren aber hier nicht vorhanden. Parallelen zu den konischen Keramikgefäßen vom 1. Jh. finden wir aus der Südwestslowakei in Bratislava-Dúbravka im Objekt 22/88 etwa aus claudisch-frühflavischer Zeit der Zeitstufen B1b-B1c (Elschek 2017, 192, Taf. 18: 7, 9), E. Droberjar reihte konische Gefäße des 2. Jh. aus Südmähren zum Typ 2600 (Droberjar 1997, 55).

\section{Katalog der Funde}

(Abb. 4)

1. Körpergrab einer Frau mit Grabbeigaben.

2. Nähnadel, Ae, L. 8,9 cm, Inv. 1730/2010.

3. Typ Almgren 68. Kräftig profilierte Fibel, Ae, eingliedrig, mit dreiteiligem Bügelknoten, kurzem verbreiterten oben gewölbten Kopfteil, Stützplatte, Sehnenhaken und Spiralrolle mit vier Windungen an jeder Seite, obere Sehne und Nadel, stabförmiger Fuß mit Knopfabschluss, trapezförmiger beschädigter Nadelhalter mit zwei kreisförmigen Öffnungen, L. 5,5 cm, Inv. 1728/2010-Kat. Fibel Nr. 80.

4. Typ Almgren 68. Kräftig profilierte Fibel, Ae, eingliedrig, mit dreiteiligem Bügelknoten, kurzem verbreiterten oben gewölbten Kopfteil, Stützplatte, Sehnenhaken und der Spiralrolle mit vier Windungen an jeder Seite, oberer Sehne und Nadel, stabförmiger Fuß mit Knopfabschluss, trapezförmiger beschädigter Nadelhalter, L. $5 \mathrm{~cm}$, Inv. 1729/2010-Kat. Fibel Nr. 83.

5. Messer. Fe, mit Gewebeabdruck auf einer Seite und der Messerkante, L. 6,2 cm, Inv. 1725/2010.

6. Kleine Henkeltasse, Dm. M. 4.9 cm, H. 3,4 cm, Inv. Ker. 387/2010.

7. Kleine konische becherförmige Schüssel, vier waagerechte Reihen von Rillen, Dm. M. 13,6 cm, H. 9,1 cm, Inv. Ker. 388/2010.

${ }^{6}$ Die anthropologische Analyse führte RNDr. Július Jakab, CSc., durch (Jakab 2015, 119, 120). 


\section{${ }^{14} \mathrm{C}$ Analyse der Knochenproben vom Körpergrab-Objekt 230/2010} (Abb. 5)

Die Knochenproben der Toten für die ${ }^{14} \mathrm{C}$ Probe (Zähne) realisierte das Laboratorium Datowań Bezwzględnych in Kraków im Jahr 2012. ${ }^{7}$ Der Median liegt um 40 n. Chr. (Abb. 5). Die Daten entsprechen etwa der konventionellen Datierung der Fibeln vom Typ Almgren 68 die wie oben erwähnt am meisten in den 30-70-er Jahren des 1. Jh. getragen wurden. Ähnliche Daten erbrachte auch $\mathrm{die}^{14} \mathrm{C}$ Datierung der Holzeinfassung vom Brunnen aus Mušov-Neurissen, der sich beim römischen Holzgebäude mit Apsis befand. Diese betrug $1970 \pm 40 \mathrm{BP}$, bzw. 50 BC-130 AD mit 95,4 \% Wahrscheinlichkeit (Groh 2015, 181, Tab. 14).

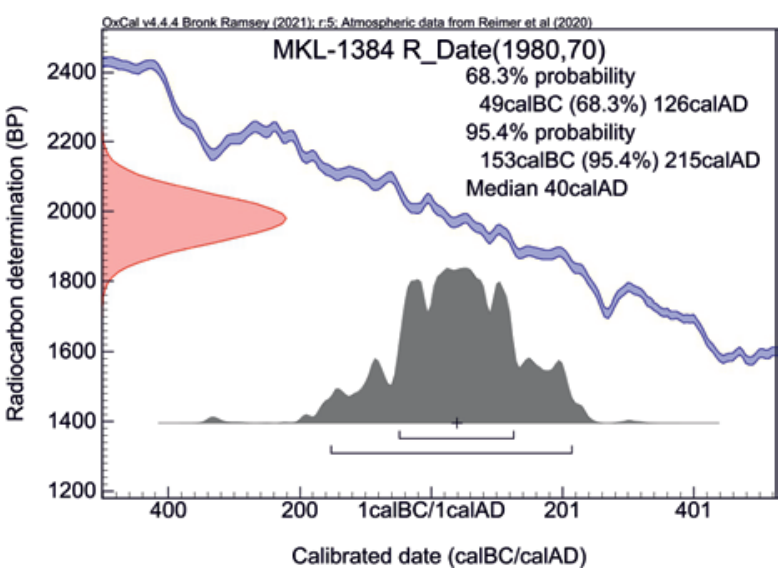

Abb. 5. Zohor-Piesky. Die ${ }^{14} \mathrm{C}$ Analyse der Knochenproben vom Körpergrab-Objekt 230/2010.

\section{LITERATUR}

Adler 1975 - H. Adler: Ein germanisches Körpergrab der Römischen Kaiserzeit in Neuruppersdorf. Fundberichte aus Österreich 14, 1975, 15-26.

Adler 1976 - H. Adler: Kaiserzeitliche Funde aus Baumgarten an der March. Mitteilungen der Anthropologischen Gesellschaft in Wien 106, 1976, 7-16.

Cociș 2019 - S. Cociș: The Brooch Workshops from Dacia and the other Danubian Provinces of the Roman Empire $\left(1^{\text {st }} \mathrm{c}\right.$. $B C-3^{\text {rd }}$ c. AD). Cluj-Napoca 2019.

Droberjar 1997 - E. Droberjar: Studien zu den germanischen Siedlungen der Älteren Römischen Kaiserzeit in Mähren. Fontes Archaeologici Pragenses 21. Praha 1997.

Droberjar 2006 - E. Droberjar: Hornolabští Svebové-Markomani. K problematice dalšího vývoje großromstedtské kultúry ve stupni Eggers B1 („Zeitgruppe 3“) v Čechách (dobřichovská skupina). Archeologie ve středních Čechách 10, 2006, 599-712.

Eggers 1949-1950 - H. J. Eggers: Lübsow. Ein germanischer Fürstensitz der älteren Kaiserzeit. Praehistorische Zeitschrift 34-35, 1949-1950, 58-111.

Eggers 1951 - H. J. Eggers: Der römische Import im freien Germanien. Atlas zur Urgeschichte 1. Hamburg 1951.

Elschek 1997 - K. Elschek: Archeologický výskum v Zohore v roku 1995. AVANS 1995, 1997, 40-43, 207-211.

Elschek 2002 - K. Elschek: Ein Hortfund von römischen Bronzegefäßbruchstücken, neue Grab- und Siedlungsfunde aus Zohor (Westslowakei). In: K. Kuzmová/K. Pieta/J. Rajtár (Hrsg.): Zwischen Rom und dem Barbaricum. Festschrift für T. Kolník zum 70. Geburtstag. Archaeologica Slovaca Monographiae. Communicationes 5. Nitra 2002, 245-260.

Elschek 2007 - K. Elschek: Der germanische Fürstensitz von Zohor (Westslowakei) während der römischen Kaiserzeit. Kurze Übersicht. Zborník SNM 101. Archeológia 17, 2007, 265-280.

Elschek 2011 - K. Elschek: Záchranný výskum v areáli A.S.A. Zohor v roku 2008. AVANS 2008, 2011, 85-87, 295.
Elschek 2013a - K. Elschek: Pokračovanie záchranného výskumu v areáli A.S.A. Zohor. In: AVANS 2009, 2013, 92, 93, 287.

Elschek $2013 b$ - K. Elschek: Zohor. Ein neues Fürstengrab der „Lübsow-Gruppe“ und Brandgräber mit Edelmetallbeigaben aus Zohor (Westslowakei). In: M. Hardt/ O. Heinrich-Tamáska (Hrsg.): Macht des Goldes, Gold der Macht. Herrschafts- und Jenseitspräsentation zwischen Antike und Frühmittelalter im mittleren Donauraum. Forschungen zu Spätantike und Mittelalter. Band 2. Akten des 23. Internationalen Symposiums der Grundproblemeder frühgeschichtlichen Entwicklung im mittleren Donauraum. Tengelic, 16.-19. 11. 2011. Weinstadt 2013, 91-123.

Elschek $2014 a$ - K. Elschek: Nové žiarové hroby z 2. polovice 2. storočia zo Zohora na západnom Slovensku. In: V. Turčan (zost.): Stĺp Marca Aurelia a stredné Podunajsko. Štúdie. Zborník SNM. Archeológia. Supplementum 8. Bratislava 2014, 41-50.

Elschek 2014b-K. Elschek: Zohor v dobe rímskej. Nový germánsky kniežací hrob a žiarové pohrebiská na Záhorí. In: B. Komoróczy (ed.): Sociální diferenciace barbarských komunit ve světle nových hrobových, sídlištních a sběrových nálezů (Archeologie barbarů 2011). Spisy Archeologického ústavu AV ČR Brno 44. Brno 2014, 113-131.

Elschek 2015 - K. Elschek: Pokračovanie záchranného výskumu v areáli A.S.A. Zohor v roku 2010. AVANS 2010, 2015, 74-77, 266-270.

Elschek 2017 -K. Elschek: Bratislava-Dúbravka im 1. bis 4. Jahrhundert n. Chr. Germanischer Fürstensitz mit römischen Bauten und die germanische Besiedlung. Archaeologica Slovaca Monographiae. Studia 29. Nitra 2017.

Elschek/Rajtár/Varsík 2011 - K. Elschek/J. Rajtár/V. Varsik: Sepulkrálny objekt zo Zohora. In: E. Droberjar (ed.): Archeologie barbarů 2010. Hroby a pohřebiště Germánů mezi Labem a Dunajem. Sborník př́spěvků ze VI. Protohistorické konferencie. Hradec Králové, 6. -9. záři 2010. Studia Archaeologica Suebica I. Olomouc 2011, 133-151.

\footnotetext{
7 Prof. dr hab. inż. Marek Krąiec.
} 
Garbsch 1965 - J. Garbsch: Die norisch-pannonische Frauentrach im 1. und 2. Jahrhundert. Münchner Beiträge zur Vor- und Frühgeschichte 11. Veröffentlichungen der Kommission zur archäologischen Erforschung des spätrömischen Raetien 5. München 1965.

Groh 2015 - St. Groh: Römische Feldlager in der MarchThaya-Region. In: St. Groh/H. Sedlmayer: Expeditiones Barbaricae. Forschungen zu den römischen Feldlagern von Engelhartstetten, Kollnbrunn und Ruhhof, Niederösterreich. Archäologische Forschungen in Niederösterreich. Neue Folge 2. Krems 2015, 154-184.

Jakab 2015 - J. Jakab: Dve kostry zo staršej doby rímskej v Zohore. AVANS 2010, 2015, 119, 120.

Jílek/Kuča/Sojková 2011 - J. Jílek/M. Kuča/T. Sojková: Pohřebište z doby římské ve Velaticích. Slovenská archeológia 59, 2011, 235-309.

Kolník 1959 - T. Kolník: Germánske hroby zo staršej doby rímskej zo Zohora, Žlkoviec a Kostolnej pri Dunaji. Slovenská archeológia 7, 1959, 144-162.

Kolník 1977 - T. Kolník: Anfänge der germanischen Besiedlung in der Südwestslowakei und das Regnum Vannianum. In: B. Chropovský (Hrsg.): Symposium Ausklang der Latène-Zivilisation und Anfänge der germanischen Besiedlung. Bratislava 1977, 143-171.

Kolník 1980 - T. Kolník: Römerzeitliche Gräberfelder in der Slowakei. Archaeologica Slovaca Monographiae. Fontes 14. Bratislava 1980.

Kraskovská 1959 - L. Kraskovská: Hroby z doby rímskej v Zohore. Slovenská archeológia 7, 1959, 99-143.

Krekovič 2014 -E. Krekovič: Miniaturgefäße im quadischen Kultur-Gebiet in der Slowakei. In: R. Madyda-Legutko/J. Rodzińska-Nowak (red.): Honoratissimum assensus genus est armis laudare. Studia dedykowane Profesorowi Piotrowi Kaczanowskiemu zokazji siedemdziesiatej rocznicy urodzin. Kraków 2014, 443-453.

Lauermann 2017 - E. Lauermann: Zum Forschungsstand der Römischen Kaiserzeit und der Völkerwanderungszeit in norddanubischen Niederösterreich. In: Na hranicích impéria. Extra fines imperii. Jaroslavu Tejralovi $k$ 80. narozeninám. Brno 2017, 235-254.

Manuskript angenommen am 19. 9. 2021

Übersetzt von Verfasser

Abstract translated by author
Lichardus 1984 - J. Lichardus: Körpergräber der frühen Kaiserzeit im Gebiet der südlichen Elbgermanen. Saarbrückener Beiträge zur Altertumskunde. Band 43. Bonn 1984.

Mączyńska 2001 - M. Mączyńska: Das Verbreitungsbild der Fibeln A. 67/68 und A. 68 im Barbarikum. Slovenská archeológia 49, 2001, 165-179.

Mitscha-Märheim 1930-H. Mitscha-Märheim: Germanische Funde aus dem Bezirk Mistelbach in Niederösterreich. Jahrbuch für Landeskunde von Niederösterreich. Neue Folge 23, 1930, 1-24.

Ondrouch 1957 - V. Ondrouch: Bohaté hroby z doby rímskej na Slovensku. Bratislava 1957.

Peškař 1972 - I. Peškař: Fibeln aus der römischen Kaiserzeit in Mähren. Praha 1972.

Pollak 1980 - M. Pollak: Die germanischen Bodenfunde des 1.-4. Jahrhunderts n. Chr. Im nördlichen Niederösterreich. Studien zur Ur- und Frühgeschichte des Donau- und Ostalpenraumes 1. Wien 1980

Schuster 2010 - J. Schuster: Lübsow. Älterkaiserzeitliche Fürstengräber im nördlichen Mitteleuropa. Bonner Beiträge zur Vor- und Frühgeschichtlichen Archäologie 12. Bonn 2010.

Sedlmayer 2009 - H. Sedlmayer: Die Fibeln vom Magdalensberg. Funde der Grabungsjahre 1948-2002 und Altfunde des 19. Jahrhunderts. Kärntner Museumsschriften 79. Archäologische Forschungen zu den Grabungenauf dem Magdalensberg 16. Klagenfurt am Wörthersee 2009.

Studeníková 1978 - E. Studeníková: Nálezy z doby bronzovej v Zohore, okr. Bratislava-vidiek. Zborník SNM 72. História 18, 1978, 9-37.

Tejral 1977 - J. Tejral: Die älteste Phase der germanischen Besiedlung zwischen Donau und March. In: B. Chropovský (Hrsg.): Symposium Ausklang der Latène-Zivilisation und Anfänge der germanischen Besiedlung. Bratislava 1977, 307-342.

Turčan 2016 - V. Turčan: Vierzehnter Jahrgang der Kolloquien zu den Fragen der römisch-germanischen Archäologie. Zborník SNM 110. Archeológia 26, 2016, 193, 194.

PhDr. Kristian Elschek, CSc

Archeologický ústav SAV

Akademická 2

SK - 94921 Nitra

kristian.elschek@savba.sk 